\title{
The impact of education on the probability of receiving periodontal treatment. Causal effects measured by using the introduction of a school reform in Norway
}

\author{
Abstract \\ The aim of the present study was to estimate the causal effect of education on the probability of \\ receiving periodontal treatment in the adult Norwegian population. In Norway, a substantial part of the \\ cost of periodontal treatment is subsidized by the National Insurance Scheme. In that case, one might \\ expect that the influence of individual resources, such as education, on receiving treatment would be \\ reduced or eliminated. Causal effects were estimated by using data on a school reform in Norway. \\ During the period 1960-1972, all municipalities in Norway were required to increase the number of \\ compulsory years of schooling from seven to nine years. The education reform was used to create \\ exogenous variation in the education variable. The education data were combined with large sets of \\ data from the Norwegian Health Economics Administration and Statistics Norway. Since \\ municipalities implemented the reform at different times, we have both cross-sectional and time-series \\ variation in the reform instrument. Thus we were able to estimate the effect of education on the \\ probability of receiving periodontal treatment by controlling for municipality fixed effects and trend \\ variables. The probability of receiving periodontal treatment increased by 1.4 to 1.8 percentage points \\ per additional year of schooling. This is a reasonably strong effect, which indicates that policies to \\ increase the level of education in the population can be an effective tool to improve oral health, \\ including periodontal health.
}

Key words: education, causal estimates, instrumental variable, periodontal treatment, observational data 


\section{Introduction}

Periodontal disease is one of the most common chronic inflammatory diseases in humans. It was ranked as the sixth most prevalent disease in the Global Burden of Disease Study from 2010 (Kassebaum et al., 2014). The estimated prevalence is about 10\% (Kassebaum et al., 2014; Jenkins \& Papapanou, 2001; Petersen, 2003). At the individual level periodontal disease can lead to tooth loss, discomfort, masticatory dysfunction and poor nutritional status. Periodontal disease is also a burden on the healthcare economy, mainly due to the cost of treating the disease (Brown, Johns, \& Wall, 2002; PrNewswire, 2008, 2014).

Periodontal disease is due to the development of a pathogenic microbial biofilm at or below the margin of the gum (Chapple, 2014; Pihlstrom et al., 2005). In patients that are susceptible, this biofilm triggers an inflammatory immune response, which destroys the bone surrounding the teeth. Periodontal disease is associated with several chronic inflammatory diseases of ageing, such as atherogenic inflammatory disease, type 2 diabetes, rheumatoid arthritis, chronic kidney disease, obesity, and chronic obstructive pulmonary disease (Chapple, 2014; Pihlstrom, Michalowicz, \& Johnson, 2005).

When the disease is established, treatment is to remove the biofilm using manual or powered instruments, including biofilm debridement of periodontal pockets. In most cases, periodontal treatment, combined with good oral hygiene, is effective in reducing tissue inflammation and pocket depths, and in maintaining the attachment of the gum to the teeth (Hirschfeld \& Wasserman, 1978; Drisko, 2001; Cobb, 2002; Pihlstrom, Ortiz-Campos, \& McHugh, 1981). Periodontal treatment is also important for prevention of recurrence of the disease (Axelsson, Nystrom, \& Lindhe, 2004; Axelsson \& Lindhe, 1981; Wennström, Serino, Lindhe, Eneroth, \& Tollskog, 1993; Becker, Becker, \& Berg, 1984; Morris, Steele, \& White, 2001; Fardal \& Grytten, 2014). 
Periodontal disease is more common among men than among women (Grossi et al., 1995; Albandar \& Kingman, 1999; Shiau \& Reynolds, 2010a). The reason for this difference is not clear. There are at least two possible explanations (Shiau \& Reynolds, 2010b; Genco, 1996). First, men usually have poorer oral hygiene than women and they have fewer preventive dental visits. Second, there may be genetic factors that contribute to gender differences in the prevalence of periodontal disease. This is supported by the results from studies that have shown that gender is associated with periodontal disease even after oral hygiene has been corrected for (Grossi et al., 1994, 1995). In a comprehensive review, Shiau and Reynolds (2010b) suggest that the sex difference is because "women seem to have a more responsive and protective cell-mediated and humoral immune response to antigenic challenges compared to males". Different gene regulation, in particular differences in sex steroid-responsive genes, most likely play a major role (University of Maryland Baltimore, 2010).

An important policy goal is to make periodontal treatment available to everybody in need of such care (Jin et al., 2011). Ideally, the probability of receiving treatment should be independent of social determinants of health, such as education, income and living conditions. Several studies have found a positive association between socioeconomic status and the prevalence of periodontal disease (for a review see Schuch, Peres, Singh, Peres, \& Do, 2016). To our knowledge there are no studies in which the relationship between socioeconomic status and the probability of receiving treatment has been examined.

The aim of the present study was to estimate the causal effect of education on the probability of receiving periodontal treatment in the adult Norwegian population. In Norway, a substantial part of the cost of periodontal treatment is subsidized by the National Insurance Scheme. In that case, one might expect that the influence of individual resources, such as education, on receiving treatment would be reduced or eliminated. 
We were able to estimate the causal effect by using data on a school reform in Norway. During the period 1960-1972, all municipalities in Norway were required to increase the number of compulsory years of schooling from seven to nine years. The education data were combined with large sets of data from the Norwegian Health Economics Administration and Statistics Norway. Since municipalities implemented the reform at different times, we have both cross-sectional and time-series variation in the reform instrument. Thus we were able to estimate the effect of education on the probability of receiving periodontal treatment by controlling for municipality fixed effects and trend variables. We found that a higher level of education substantially improved access, measured as an increase in the likelihood of obtaining treatment.

Below we first briefly describe the background for the study - among other things the theory underlying using school reforms for identification of causal effects. We then describe the data and the empirical model. Finally, the results are presented and discussed.

\section{Theory and background}

An important focus of our study was to estimate causal effects. This is because a causal estimate can be used to make valid predictions about the consequences of a change in education. For example, does more schooling for people with poor dental health improve the probability of receiving treatment for periodontal disease? An association, typically estimated by ordinary least squares (OLS) regression, may not reflect a causal relationship (Grossman, 2006; Eide \& Showalter, 2011; Listl, Jürges, \& Watt, 2016). Such an association is likely to lead to biased results, mainly because the estimation does not take account of unobserved variables that are correlated with both education and treatment. Unobserved variables that are frequently cited in the literature are ability, place of residence, time preferences and morbidity (Grossman, 2006; Oreopoulos \& Salvanes, 2011; Grossman \& Kaestnar, 1997). 
For example, smarter individuals may be more likely to obtain more schooling, and when necessary, to seek dental care, including periodontal treatment when necessary. Further, highly educated and wealthy individuals tend to live in affluent areas. These are also areas where the supply and quality of both schooling and dental services are likely to be high. Decisions about education and health involve trade-offs of different outcomes over time (Fuchs, 1982; Farrell \& Fuchs, 1982). How does the individual trade off current outcomes over future outcomes? People with a strong preference for the future relative to the present are more likely to invest in education, and at the same time they are more likely to engage in healthier activities, such as having periodontal treatment. Conversely, people who value the present highly will invest less in both education and healthy activities, such as looking after their teeth. Therefore, time preferences must be controlled for (Ippolito, 2003; Van der Pol, 2011). As ability, place of residence and time preferences are positively correlated with both education and treatment, omission of these variables would lead to an upward bias of the OLS estimate. Morbidity is likely to be positively correlated with treatment and negatively correlated with education. Therefore, unless morbidity is taken account of by the identification strategy, the OLS estimate will be downward biased.

One way to control for unobserved variables is to use instrumental variables. So far, within the social science literature, the most promising type of instrumental variable has been the introduction of compulsory schooling laws (Eide \& Showalter, 2011; Mazumder, 2012). Such laws were introduced in several European and North American countries in different time periods during the last century.

Typically, the effect of these laws was that the number of years of compulsory schooling was increased. In several countries, the number of years of compulsory schooling was increased from 7 to 9 years during the 1960s and the 1970s (Gathmann, Jürges, \& Reinhold, 2015). The laws were implemented at a national level and encompassed all preschool children. The "treatment" group was then comprised of children with 9 years of compulsory education, and the "control" group was comprised of children with 7 years of compulsory education. 
Several economists have used the random variation induced by the introduction of compulsory schooling to estimate causal effects of education on different types of health outcome measures (for example see: Lleras-Muney, 2005; Clark \& Royer, 2013; Van Kippersluis, O’Donell, \& Van Doorslaer, 2011; Fletcher, 2015; Braakmann, 2011; Lager \& Torssander, 2013; Arendt, 2005; Kemptner, J“rges, \& Reinhold, 2011; Grytten, Skau, \& Sørensen, 2014; Albuoy \& Lequien, 2009; Auld \& Sidhu, 2005). Such studies have been performed in the United States, Great Britain, the Netherlands and the Scandinavian countries. In several of the studies, but not all of them, a causal effect of education has been found (for a review see: Mazumder, 2012; Gathmann et al., 2015). For example, Oreopoulos (2007), using the introduction of compulsory schooling laws in the USA, Canada and the United Kingdom, found that an extra year of schooling at the age of 14 led to an increase in lifetime wealth of $15 \%$, and to better mental and physical health. This was a consistent finding across all countries. Brunello, Fort, Schneeweis, \& Winter-Ebmer (2016) investigated the causal effects of education on different health measures in 7 European countries. They found that one additional year of schooling reduced self-reported poor health by 4 to 6 percentage points, and led to less smoking, less drinking and more exercise. Powdthavee (2010) claims that part of the beneficial effect of more schooling on health, is a reduction in individuals' stress level. This is supported by his finding that an extra year of schooling reduced the probability of having hypertension by nearly 10 percentage points. In a few studies, no causal effect of education on health has been found (Arendt, 2005; Albuoy \& Lequien, 2009; Auld \& Sidhu, 2005). In France, the minimum school leaving age was raised from 14 to 16 years in 1953. Albouy and Lequien (2009), using this increase in schooling, found no effect on mortality at the age of 50 years. A consistent finding in nearly all studies is that the regression coefficient from the instrumental variable estimation is different from the OLS estimation (for a review see: Mazumder, 2012; Gathmann et al., 2015). This underscores the importance of using a statistical technique in which confounding variables have been controlled for. To our knowledge, there are no studies within dentistry in which instrumental variables have been used to estimate the effect of education on any dental outcome. 


\section{Material and Methods}

\subsection{Identification using a compulsory school reform in Norway}

From 1960 and onwards a school reform was implemented in Norway. Comprehensive descriptions of the reform are given by: Grytten et al., 2014; Aakvik, Salvanes, \& Vaage, 2010; Lie, 1973; Telhaug, 1969. There are two key elements with this reform that need to be understood:

First, the reform increased the minimum number of years of schooling from seven to nine years. The school year was from mid August until mid June both before and after the reform. Before the reform, children started school in the year they became seven, i.e. they were between six and a half and seven and a half years of age when they started school. They finished their compulsory schooling at age 14. When the new scheme was introduced, children still started school in the year they became seven, but finished their compulsory schooling the year they became 16 .

Second, for more than a decade Norway had two separate school systems. Which system the child was in depended on which municipality he/she lived in, and in which year he/she was born. The children in the first birth cohort who could start nine years compulsory schooling were born in 1947 , and those in the last cohort to finish in the old system were born in 1958. The time of implementation was decided by the individual municipalities, but all had to implement the reform by the end of 1972 .

This school reform has been used as an instrumental variable in several papers to study causal effects of education on the following outcomes: intergenerational transmission of education, family size, teenage births, mobility in the labour market, IQ and earnings (Aakvik et al., 2010; Black, Devereux, \& Salvanes, 2005, 2007, 2008, 2010; Machin, Salvanes, \& Pelkonen, 2012). The current dataset has been designed in a similar way to the design of Salvanes and co-workers (for details see Aakvik et al., 2010; Black et al., 2005). Thus our main analysis was performed on a sample that was restricted to individuals with 9 years or less of education. Black et al. (2005) have examined the 
strengths and weaknesses of using a restricted sample (9 years or less of education) as opposed to the full sample (all lengths of education). They concluded that estimation using the restricted sample was preferred to estimation using the full sample. The reason is that with the restricted sample they were "able to estimate a much stronger first stage and obtain more precisely estimated second-stage coefficients". They showed, at the same time, by doing several robustness-tests, that the coefficients from the restricted sample were not biased.

We identified the timing of the reform for 706 of the 735 municipalities that existed in 1960. The municipalities implemented the reform at different times, as shown in Fig. 1. We used the 1960 census to identify the municipality that each of the individuals grew up in. The individuals would then have been between 2 and 13 years of age, i.e. at an age where they would have been affected by the reform during the following years. We had no data on the timing of the reform for 29 municipalities. Therefore, we had to exclude all individuals in these municipalities from our sample. These individuals represent $3.2 \%$ of individuals with 9 years or less of education. It is not possible to determine whether this led to bias in our results. However, we believe that it is reasonable to assume that, if bias exists, it will be low.

\section{(Fig. 1 here)}

The key advantage of this design is the time series variation across municipalities. We could compare individuals in the same municipality who were subjected to 9 years of compulsory schooling with those who were not. Since municipalities implemented the reform at different points in time, we were able to include municipality fixed effects in the regression model. Therefore, all unobserved crosssectional variation between municipalities that could be correlated with individuals' level of education and the probability of receiving periodontal treatment was cancelled out.

Let subscript $\mathrm{mtj}$ denote an individual $\mathrm{j}$ who has grown up in municipality $\mathrm{m}$, and was born in year t. $R_{m t j}$ is a dummy variable that equals 1 if the individual was 14 years or younger when the reform was 
introduced in the municipality, (i.e. he/she was affected by the reform), and 0 otherwise. $\mathrm{T}_{\mathrm{mt}}$ is a centred linear trend variable, i.e. defined as zero the first year of the reform. Since municipalities implemented the reform at different points in time, the trend variable is defined by the timing of the reform. The after-reform trend was flat when we restricted the sample to individuals with a maximum of nine years of education. We therefore allowed the model to have different time trends before and after the reform. This was captured by the interaction term between reform $\left(\mathrm{R}_{\mathrm{mt}}\right)$ and time-trend $\left(\mathrm{T}_{\mathrm{mt}}\right)$. The first stage regression for the individual's years of education $\left(\mathrm{E}_{\mathrm{mtj}}\right)$ can be written as:

$$
E_{m t j}=\gamma_{0} R_{m t}+\gamma_{1} T_{m t} R_{m t}+\gamma_{2} T_{m t}+\text { Fixed effect for year of birth }+ \text { Municipality fixed effects }+e_{m t j}
$$

In additional analyses we also interacted the trend variable $\left(\mathrm{T}_{\mathrm{mt}}\right)$ with municipality fixed effects to capture municipality-specific trends. We do not report the results from these additional analyses, since the main results, as shown in Table 3, did not change after the inclusion of these municipality-specific trends.

Let $\hat{E}_{\mathrm{mtj}}$ be the predicted value of the individual's years of education from the first stage regression, and the probability of obtaining treatment for periodontal disease $\left(\mathrm{PC}_{\mathrm{mtj}}=1\right)$ be the dependent variable. The treatment involves professional debridement of the teeth; i.e. subgingival scaling and/or root planing. A minority of the patients, less than $10 \%$ in our data, have periodontal surgery (flap or gingivectomi). The second stage regression is then:

$$
P C_{m t j}=\beta_{0} \hat{E}_{m t j}+\beta_{1} T_{m t}+\text { Fixed effect for year of birth }+ \text { Municipality fixed effects }+v_{m t j}
$$

Below, we present results based on samples with three time periods: 1) two years before to two years after the reform, 2) four years before to four years after the reform, and 3) six years before to six years after the reform. It is reasonable to assume that if more years are included in the analyses, our estimates are more vulnerable to bias, due to unobservable variables. One way to reduce the possibility for such bias is to include fewer years. With fewer years (for example two years before to two years 
after the reform) the individuals who were not affected by the reform (just before) and the individuals who were affected (just after) would be more similar in relation to unobservable variables. In that way the likelihood of bias would be reduced. Naturally, with a narrow bandwidth the precision of the regression estimate may not be that high (large standard errors due to few individuals). By extending the number of years (a broader bandwidth) the regression estimate would become more precise, but at the risk of being biased. The bias would be small if the regression coefficient estimated in the sample with the broader bandwidth was not very different from the coefficient estimated in the sample with the narrower bandwidth. We used a linear probability model in the estimation (Angrist, 2001). The standard errors were clustered at the municipal level to take account of serial correlations and withinmunicipal correlation (Cameron \& Miller, 2015).

\subsection{Data}

In Norway, all patients 20 years and above who receive treatment for periodontal disease have most of their costs covered by the National Insurance Scheme (Ministry of Health and Care Services, 2014). Reimbursement payments are administered by the Norwegian Health Economics Administration (Norwegian Health Economics Administration, 2017). Due to a generous reimbursement system, it is reasonable to assume that virtually all adults who receive treatment are registered with the Norwegian Health Economics Administration. Thus for these adults, the dependent variable in Equation (2) equals 1. If not registered, the dependent variable equals 0 . We used the data for 2013, since that was the first year they were available electronically.

All persons who live in Norway have a unique personal identification number. This made it possible to merge the data from the Norwegian Health Economics Administration with two data registers in Statistics Norway. The first register, the Norwegian Standard Classification of Education (Statistics Norway, 2000), contains information about the highest education of all persons living in 
Norway from 1967. The second register, the Population and Housing Census, contains information about place of residence (municipality) of all persons living in Norway in 1960 (Statistics Norway, 1987). By merging data from the Norwegian Health Economics Administration with data from Statistics Norway, our final data file encompasses the whole adult population. Most immigrants to Norway have not been exposed to the school reform (Grytten, Skau, \& Sørensen, 2013). Therefore they were not included in our analyses.

\section{Results}

\subsection{OLS estimates}

The proportion of individuals who had received treatment for periodontal disease was about $10 \%$ in all three samples (Table 1). This proportion is similar to the proportion of periodontal disease that has been reported in numerous studies (Kassebaum et al., 2014; Jenkins \& Papapanou, 2001; Petersen, 2003).

Education had a positive effect on the probability of receiving treatment for periodontal disease. The sizes of the regression coefficients were in the range 0.006 to 0.010 (Table 2). This implies that the probability of obtaining treatment increased by 0.6 to 1.0 percentage points per additional year of schooling.

\subsection{First stage estimates}

The reform resulted in $0.56-0.81$ years of additional schooling (Table 3). The sizes of the coefficients for the effects of the reform on years of education are well within the range that Salvanes and co-workers report from their studies (Black et al., 2008; Machin et al., 2012). 
The regression coefficients were highly significant, with t-values ranging from 52 (two years before to two years after the reform) to 173 (six years before to six years after the reform). This means that we have high F-values for the instrumental variable, fulfilling all the criteria proposed in the literature for a strong instrument (Stock, Wright, \& Yogo, 2002).

The sign of the regression coefficient for the trend variable was positive. This indicates that educational levels increased over time prior to the reform. The post-reform trend is given by the sum of the trend coefficient and the reform $\mathrm{x}$ trend coefficient. That sum was close to zero. This is because our sample was restricted to individuals who had maximum 9 years of education.

\subsection{Second stage estimates}

In all three samples, education had a positive effect on the probability of receiving treatment for periodontal disease (Table 3). The sizes of the regression coefficients were fairly similar in all samples; ranging from 0.014 to 0.018 . This implies that the probability of receiving treatment increased by 1.4 to 1.8 percentage points per additional year of schooling.

In the analyses with the broader bandwidth, the estimate is clearly more precise than the estimate with the narrower bandwidth. However, the two estimates are fairly similar; i.e. the bias by having a broader bandwidth is small.

\subsection{Supplementary analyses}

In order to test the robustness of our results, we carried out additional analyses.

First, we did three placebo tests. These tests were used to test the validity of the instrumental variable. This is an experiment in which we pretend that the increase in the number of years of schooling was introduced earlier than it actually was. In such an experiment, we do not expect the 
reform to have any effect on the probability of obtaining treatment for periodontal disease. If there is an effect, the instrumental variable would be correlated with a third variable. Then we have a poor instrument.

In our three tests we pretended that the reform was introduced in the municipalities one, two and three years earlier than it actually was introduced. The results from the second stage regressions are presented in Table 4 . The variable measuring the number of years of education was far from being statistically significant at conventional levels. Also, the regression coefficients were small in value, and they had the incorrect sign. These results stand in clear contrast to the second stage estimates from the main analyses as presented in Table 3.

Second, we extended our main analyses by including the following control variables: gender, single person household, unemployment benefits and disability pension (2013 figures). This was done to test the exogenity assumption of our instrumental variable. That assumption requires that the school reform increases the probability of obtaining treatment for periodontal disease only through more schooling. In that case the instrumental variable is not correlated with the error term in the regression equation; i.e. biases due to confounding are eliminated.

The second stage estimates are reported in Table 5. The regression coefficients for gender and disability pension had statistically significant effects on the probability of obtaining treatment for periodontal disease $(\mathrm{p}<0.05)$. For gender, the sizes of the regression coefficients were fairly similar in all samples, ranging from -0.039 to -0.035 . This implies that the probability of receiving treatment increased by 3.9 to 3.5 percentage points for women compared to for men. However, the coefficient for our schooling variable was not influenced by the inclusion of the control variables. That gives some support to the belief that our instrumental variable is not biased due to confounding variables.

In Table 5, there were missing values for the variables measuring unemployment benefits and disability pension. Individuals with missing values for these variables were excluded from the 
analyses. The number of individuals with missing values varied according to the time period for inclusion of data (the bandwidths). There was no bandwidth for which the percentage of individuals with missing values was above $3 \%$. This figure is so small that it is unlikely that this has led to bias.

Third, we tested whether the effect of education varied according to gender. This was done by respecifying Equation (2) by including an interaction term between gender and the predicted value of the individual's years of education $\left(\hat{\mathrm{E}}_{\mathrm{mt}}\right)$. Equation (1) was re-specified to include two endogenous variables: years of schooling $\left(\mathrm{E}_{\mathrm{mtj}}\right)$, and an interaction term between years of schooling $\left(\mathrm{E}_{\mathrm{mtj}}\right)$ and gender.

The second stage estimates are reported in Table 6. The regression coefficient for the interaction term between gender and education $\left(\hat{\mathrm{E}}_{\mathrm{mtj}}\right)$ was small in absolute value, and far from being statistically significant at conventional levels $(\mathrm{p}<0.05)$. This implies that increased schooling does not contribute to a reduction of the gender difference in the probability of receiving periodontal treatment.

\section{Discussion}

We found an effect of education on the probability of obtaining treatment for periodontal disease. The causal estimates were larger than the estimates from the OLS regressions. This indicates that morbidity is an important confounding variable that has been omitted from the OLS estimation. Ability, place of residence and time preferences are not likely to be important confounders. This is because the OLS estimate is downward rather than upward biased. Our results from the instrumental variable estimation underscore the importance of using a statistical technique in which confounding variables have been controlled for. These variables are unobserved, hence their individual effects cannot be estimated. 
Our study was performed using panel data. Use of panel data is a great advantage, as it makes it possible to perform a placebo test (Jones, 2007). Such a test can be used to assess the validity of the instrumental variable. A placebo test provides counter evidence by estimating a model in a context where no effect should be found. If an apparent effect is found, then the validity of the instrumental variable is questionable (Jones, 2007). The results from the placebo tests indicate that our results are not biased due to unobservable variables. A further strength of our study is that the criterion about instrument relevance is fulfilled (Martens, Pestman, Boer, Belitser, \& Klungel, 2006). According to that criterion the reform must explain a substantial part of the variation in number of years of schooling. That is the case with the Norwegian school reform.

In our study, selective migration may be a concern: families could have moved from a non-reform municipality in order to select a reform municipality. We cannot identify these families from our data. Therefore, it is not possible to control for selective migration in our analyses. This might have led to a small, but probably not significant bias, in our results. Very few children moved in Norway in the 1960s. Yearly, only $2.5 \%$ of children in the age group $7-14$ years moved from one municipality to another (Statistics Norway, 1968). The proportion of children who moved from a non-reform municipality to a reform municipality would be less than this figure. A similar school reform was implemented in Sweden in the 1960s. The Swedish population is fairly similar to the Norwegian population with respect to socio-demographic characteristics. Meghir and Palme (2005) were able to identify at the individual level those children who moved from a non-reform municipality to a reform municipality $(=4.6 \%)$. In that way they could control for selective migration in their analyses. They found no evidence that selective migration led to any bias in their results.

The results from this study can be understood within the framework of the Grossman Model. The model was developed during the early 1970s (Grossman, 1972). Since then, it has been used as the theoretical framework for nearly all studies within the field of economics where the effect of education on any health outcome has been examined (for a review see: Grossman \& Kaestner, 1997; Grossman, 
2006). The core idea in the Grossman Model is that education improves one's stock of skills.

According to Grossman, skills make educated people more efficient producers of health than less educated people. In particular, educated people absorb and process information so that they can make healthy choices. This is termed allocative efficiency. In short, it is expected that with more schooling, people will make better and more sensible decisions about how to maintain good oral health. That involves, among other things, having periodontal treatment when necessary. Our results show that this decision is influenced by people's level of education.

In most western European countries, there has been a marked increase in the level of education during the last decades (Dolton, Asplund, \& Barth, 2009). This is a result of public policies, where a particular focus has been to increase the number of years of compulsory schooling from 7 to 9 years (Gathmann et al., 2015). One implication of these policies has been to raise the demand for periodontal treatment. In Norway, the authorities have responded to this increase in demand by training a sufficient number of dentists and specialists (Grytten \& Lund, 1999). In that way the supply side of the market has adjusted to the demand side so that rationing of the services has been avoided (Grytten \& Holmgren, 2017).

Men are less likely than women to obtain periodontal treatment (Tables 5-6). This is the case even though periodontal disease is more common among men than among women. For example, in a study from Norway, Albander, Rise, Gjermo, and Johansen (1986) found that the mean bone loss among men was nearly $40 \%$ higher than among women. Similar results are reported from other Norwegian studies, for example see: Albandar, 1990; Hansen, Bjertness, \& Gjermo, 1990; Fardal, Johannessen, \& Linden, 2004). It is not obvious which strategy is most effective in reducing the gender difference in the probability of receiving periodontal treatment (Watt, 2007). We have shown that one strategy, that is to increase the number of years of schooling, is not effective (Table 6). 
Within dentistry, there are numerous studies where the association between dental care utilization and education has been examined (for example see the review by Petersen \& Holst, 1995). These are all correlation studies. To our knowledge, there are no studies within dentistry where the causal effect of education on utilization of dental services has been estimated. We have estimated the causal effect on one type of utilization: the probability of receiving periodontal treatment. The instrumental variable methodology used in our study can easily be used to estimate causal effects on any type of dental outcome. An area of special interest would be dental health outcome, such as number of teeth, level of caries and periodontal disease, and patients' subjective assessments of their own dental health. We were not able to perform analyses with such outcome measures due to lack of appropriate data.

Within dentistry, there is a growing interest in seeking causal inference from observational data (Listl et al., 2016). We have used an instrumental variable methodology. There are other designs as well: twins and siblings design, differences-in-differences design, and regression discontinuity design. These are designs that each have their strengths and weaknesses. However, they are powerful designs if used on the right type of data, and as long as the underlying statistical assumptions for the estimation are fulfilled (Listl et al., 2016). None of these designs were appropriate to use with our data.

In conclusion, we have estimated the casual effect of education on the probability of obtaining treatment for periodontal disease. We found a reasonably strong effect: the probability of receiving treatment increased by 1.4 to 1.8 percentage points per additional year of schooling. Our results indicate that policies to increase the level of education in the population can be an effective tool to improve oral health, including periodontal health. 


\section{References}

Aakvik, A., Salvanes, K.G., \& Vaage, K. (2010). Measuring heterogeneity in the returns to education using an education reform. European Economic Review, 54(4), 483-500.

Albandar, J.M. (1990). Some predictors of radiographic alveolar bone height reduction over 6 years. Journal of Periodontal Research, 25(3), 186-192.

Albandar, J.M., \& Kingman, A. (1999). Gingival recession, gingival bleeding, and dental calculus in adults 30 years of age and older in the United States, 1988-1994. Journal of Periodontology, 70(1), 30-43.

Albandar, J.M, Rise, J., Gjermo, P., \& Johansen, J.R. (1986). Radiographic quantification of alveolar bone level changes. Journal of Clinical Periodontology, 13(3), 195-200.

Albuoy, V., \& Lequien, L. (2009). Does compulsory education lower mortality? Journal of Health Economics, 28(1), 155-168.

Angrist, J.D. (2001). Estimation of limited dependent variable models with dummy endogenous regressors. Journal of Business \& Economic Statistics, 19(1), 2-28.

Arendt, J.N. (2005). Does education cause better health? A panel data analysis using school reforms for identification. Economics of Education Review, 24(2), 149-160.

Auld, M.C., \& Sidhu, N. (2005). Schooling, cognitive ability and health. Health Economics, 14(10), 1019-1034.

Axelsson, P., \& Lindhe, J. (1981). The significance of maintenance care in the treatment of periodontal disease. Journal of Clinical Periodontology, 8(4), 281-294.

Axelsson, P., Nystrom, B., \& Lindhe, J. (2004). The long-term effect of a plaque control program on tooth mortality, caries and periodontal disease in adults. Results after 30 years of maintenance. Journal of Clinical Periodontology, 31(9), 749-757. 
Becker, W., Becker, B.E., \& Berg, L.E. (1984). Periodontal treatment without maintenance: A retrospective study in 44 patients. Journal of Periodontology, 55(9), 505-509.

Black, S.E., Devereux, P.J., \& Salvanes, K.G. (2005). Why the apple doesn't fall far: Understanding intergenerational transmission of human capital. American Economic Review, 95(1), 437-449.

Black, S.E., Devereux, P.J., \& Salvanes, K.G. (2007). From the cradle to the labor market? The effect of birth weight on adult outcomes. The Quarterly Journal of Economics, 122(1), 409439.

Black, S.E., Devereux, P.J., \& Salvanes, K.G. (2008). Staying in the classroom and out of the maternity ward? The effect of compulsory schooling laws on teenage births. The Economic Journal, 118(530), 1025-1054.

Black, S. E., Devereux, P.J., \& Salvanes, K.G. (2010). Small family, smart family? Journal of Human Resources, 45(1), 33-58.

Braakmann, N. (2011). The causal relationship between education, health and health related behaviour: Evidence from a natural experiment in England. Journal of Health Economics, 30(4), 753-763.

Brown, L.J., Johns, B.A., \& Wall, T.P. (2002). The economics of periodontal diseases. Periodontology 2000, 29(1), 223-234.

Brunello, G., Fort, M., Schneeweis, N., \& Winter-Ebmer, R. (2016). The causal effect of education on health: What is the role of health behaviors? Health Economics, 25(3), 314-336.

Cameron, A.C., \& Miller, D.L. (2015). A practitioner's guide to cluster-robust inference. Journal of Human Resources, 50(2), 317-372.

Chapple, I.L. (2014). Time to take periodontitis seriously. Bmj, 348 (Apri1 10). 
Clark, D., \& Royer, H. (2013). The effect of education on adult mortality and health: Evidence from Britain. American Economic Review, 103(6), 2087-2120.

Cobb, C.M. (2002). Clinical significance of non-surgical periodontal therapy: an evidence-based perspective of scaling and root planing. Journal of Clinical Periodontology, 29(S2), 22-32.

Dolton, P., Asplund, R., \& Barth, E. (2009). Education, wage inequality and the labour market. In P. Dolton, R. Asplund, \& E. Barth (Eds.), Education and inequality across Europe (pp. 1-23). Cheltenham: Edward Elgar.

Drisko, C.H. (2001). Nonsurgical periodontal therapy. Periodontology 2000, 25(1), 77-88.

Eide, E.R., \& Showalter, M.H. (2011). Estimating the relation between health and education: What do we know and what do we need to know? Economics of Education Review, 30(5), 778-791.

Fardal, Ø., \& Grytten, J. (2014). Applying quality assurance in real time to compliant long-term periodontal maintenance patients utilizing cost-effectiveness and cost utility. Journal of Clinical Periodontology, 41(6), 604-611.

Fardal, Ø., Johannessen, A.C., \& Linden, G.J. (2004). Tooth loss during maintanance following periodontal treatment in a periodontal practice in Norway. Journal of Clinical Periodontology, $31(7), 550-555$.

Farrell, P., \& Fuchs, V.R. (1982). Schooling and health: the cigarette connection. Journal of Health Economics, 1(3), 217-230.

Fletcher, J.M. (2015). New evidence of the effects of education on health in the US: Compulsory schooling laws revisited. Social Science \& Medicine, 127, 101-107.

Fuchs, V.R. (1982). Time preference and health: An exploratory study. In V.R. Fuchs (Ed.), Economic aspects of health (pp. 93-120). Chicago: University of Chicago Press for the National Bureau of Economic Research. 
Gathmann, C., Jürges, H., \& Reinhold, S. (2015). Compulsory schooling reforms, education and mortality in twentieth century Europe. Social Science \& Medicine, 127, 74-82.

Genco, R.J. (1996). Current view of risk factors for periodontal diseases. Journal of Periodontology, 67(10), 1041-1049.

Grossi, S., Genco, R., Machtet, E., Ho, A., Koch, G., Dunford, R., Hausmann, E. (1995). Assessment of risk for periodontal disease. II. Risk indicators for alveolar bone loss. Journal of Periodontology, 66(1), 23-29.

Grossi, S.G., Zambon, J.J., Ho, A.W., Koch, G., Dunford, R.G., Machtei, E.E., Genco, R.J. (1994). Assessment of risk for periodontal disease. I. Risk indicators for attachment loss. Journal of Periodontology, 65(3), 260-267.

Grossman, M. (1972). On the concept of health capital and the demand for health. Journal of Political Economy, 80(2), 223-255.

Grossman, M. (2006). Education and nonmarket outcomes. In E.A. Hanushek, \& F. Welch (Eds.), Handbook of the economics of education. Amsterdam: Elsevier.

Grossman, M., \& Kaestnar, R. (1997). Effects of education on health. In J.R. Behrman, \& N. Stacey (Eds.), The social benefits of education. Ann Arbor: The University of Michigan Press.

Grytten, J., \& Lund, E. (1999). Future demand for dental care in Norway; a macro-economic perspective. Community Dentistry and Oral Epidemiology, 27(5), 321-330.

Grytten, J., Skau, I., \& Sørensen, R. (2013). Do mothers decide? The impact of preferences in healthcare. Journal of Human Resources, 48(1), 142-168.

Grytten, J., Skau, I., \& Sørensen, R. J. (2014). Educated mothers, healthy infants. The impact of a school reform on the birth weight of Norwegian infants 1967-2005. Social Science \& Medicine, $105,84-92$. 
Grytten, J., \& Holmgren, T.K. (2017). De private spesialistene i tannhelsetjenesten - har de nok å gjøre? Den norske Tannlegeforenings Tidende, 127(3), 236-240.

Hansen, B.F., Bjertness, E., \& Gjermo, P. (1990). Changes in periodontal disease indicators in 35year-old Oslo citizens from 1973 to 1984. Journal of Clinical Periodontology, 17(4), 249-254.

Hirschfeld, L., \& Wasserman, B. (1978). A long-term survey of tooth loss in 600 treated periodontal patients. Journal of Periodontology, 49(5), 225-237.

Ippolito, R. (2003). Education versus savings as explanations for better health: evidence from the health and retirement survey (George Mason Law \& Economics Research Paper No. 03-04). Arlington: George Mason University School of Law.

Jenkins, W.M., \& Papapanou, P.N. (2001). Epidemiology of periodontal disease in children and adolescents. Periodontology 2000, 26(1), 16-32.

Jin, L.J., Armitage, G.C., Klinge, B., Lang, N.P., Tonetti, M., \& Williams, R.C. (2011). Global oral health inequalities: Task Group - periodontal disease. Advances in Dental Research, 23(2), 221-226.

Jones, A.M. (2007). Identification of treatment effects in health economics. Health Economics, 16(11), 1127-1131.

Kassebaum, N.J., Bernabe, E., Dahiya, M., Bhandari, B., Murray, C.J., \& Marcenes, W. (2014). Global burden of severe periodontitis in 1990-2010: A systematic review and meta-regression. Journal of Dental Research, 93(11), 1045-1053.

Kemptner, D., Jürges, H., \& Reinhold, S. (2011). Changes in compulsory schooling and the causal effect of education on health: Evidence from Germany. Journal of Health Economics, 30(2), 340354. 
Lager, A.C., \& Torssander, J. (2012). Causal effect of education on mortality in a quasi-experiment on 1.2 million Swedes. Proceedings of the National Academy of Sciences, 109(22), 8461-8466.

Lie, S.S. (1973). Regulated social change: A diffusion study of the Norwegian comprehensive school reform. Acta Sociologica, 16(4), 332-352.

Listl, S., Jürges, H., \& Watt, R.G. (2016). Causal inference from observational data. Community Dentistry and Oral Epidemiology, 44(5), 409-415.

Lleras-Muney, A. (2005). The relationship between education and adult mortality in the United States. Review of Economic Studies, 72(1), 189-221.

Machin, S., Salvanes, K.G., \& Pelkonen, P. (2012). Education and mobility. Journal of the European Economic Association, 10(2), 417-450.

Martens, E.P., Pestman, W.R., Boer, A.D., Belitser, S.V., \& Klungel, O.H. (2006). Instrumental variables: application and limitations. Epidemiology, 17(3), 260-267.

Mazumder, B. (2012). The effects of education on health and mortality. Nordic Economic Policy Review, 1, 261-303.

Meghir, C., \& Palme, M. (2005). Educational reform, ability, and family background. American Economic Review 95(1), 414-424.

Ministry of Health and Care Services. (2014). Forskrift om støndad til dekning av utgifter til unders $\varnothing$ kelse og behandling hos tannlege og tannpleier for sykdom. Retrieved May 23, 2017, from https://lovdata.no/dokument/SF/forskrift/2014-12-16-1702.

Morris, A.J., Steele, J., \& White, D.A. (2001). Adult dental health survey: The oral cleanliness and periodontal health of UK adults in 1998. British Dental Journal, 191(4), 186-192.

Norwegian Health Economics Administration. (2017). About Helfo. Retrieved May 23, 2017, from https://helfo.no/english/about-helfo. 
Oreopoulos, P. (2007). Do dropouts drop out too soon? Wealth, health and happiness from compulsory schooling. Journal of Public Economics, 91(11-12), 2213-2229.

Oreopoulos, P., \& Salvanes, K.G. (2011). Priceless: The nonpecuniary benefits of cchooling. Journal of Economic Perspectives, 25(1), 159-184.

Petersen, P.E. (2003). The World Oral Health Report 2003: continuous improvement of oral health in the 21st century - the approach of the WHO Global Oral Health Programme. Community Dentistry and Oral Epidemiology, 31(S1), 3-24.

Petersen, P.E., \& Holst, D. (1995). Utilization of dental health service. In L.K. Cohen,\& H.C. Gift (Eds.), Disease prevention and oral health promotion (pp. 342-386). Copenhagen: Munksgaard.

Pihlstrom, B.L., Michalowicz, B.S., \& Johnson, N.W. (2005). Periodontal diseases. The Lancet, 366(9499), 1809-1820.

Pihlstrom, B.L., Ortiz-Campos, C., \& McHugh, R.B. (1981). A randomized four-year study of periodontal therapy. Journal of Periodontology, 52(5), 227-242.

Powdthavee, N. (2010). Does education reduce the risk of hypertension? Estimating the biomarkereffect of compulsory schooling in England. Journal of Human Capital, 4(2), 173-202.

PRNewswire. (2008). Britain's plaque plague costing NHS more then GBP 2 billion. Retrieved May 23, 2017, from http://www.prnewswire.co.uk/news-releases/britains-plaque-plague-costing-nhsmore-than-gbp-2-billion-158904185.html.

PRNewswire. (2014). New research continues to show medical cost savings and reduced hospitalizations possible with gum disease treatment. Retrieved May 23, 2017, from http://www.prnewswire.com/news-releases/new-research-continues-to-show-medical-cost$\underline{\text { savings-and-reduced-hospitalizations- possible-with-gum-disease-treatment-251426911.html. }}$. 
Schuch, H.S., Peres, K.G., Singh, A., Peres, M.A., \& Do, L.G. (2016). Socioeconomic position during life and periodontitis in adulthood: a systematic review. Community Dentistry and Oral Epidemiology, 45(3), 201-208.

Shiau, H.J., \& Reynolds, M.A. (2010a). Sex differences in destructive periodontal disease: a systematic review. Journal of Periodontology, 81(10), 1379-1989.

Shiau, H.J., \& Reynolds, M.A. (2010b). Sex differences in destructive periodontal disease: exploring the biologic basis. Journal of Periodontology, 81(11), 1505-1517.

Statistics Norway. (1968). Statistisk Årbok 1968 (pp. 1, 29). Oslo: Statistics Norway. Retrieved May 23, 2017, from https://www.ssb.no/a/histstat/aarbok/1968.pdf.

Statistics Norway. (1987). Folke- og boligtellingene 1960, 1970 og 1980. Dokumentasjon av de sammenlignbare filene. Oslo-Kongsvinger: Statistics Norway.

Statistics Norway. (2000). Norwegian standard classification of education. Revised 2000. OsloKongsvinger: Statistics Norway.

Stock, J.H., Wright, J.H., \& Yogo, M. (2002). A survey of weak instruments and weak identification in generalized method of moments. Journal of Business \& Economic Statistics, 20(4), 518-529.

Telhaug, A.O. (1969). Den 9-årige skolen og differensieringsproblemet. En oversikt over den historiske utvikling og den aktuelle debatt. Oslo: Lærerstudentenes Forlag.

University of Maryland Baltimore. (2010). Sex hormones may explain higher risk of gum disease in men. ScienceDaily. Retrieved May 23, 2017, from www.sciencedaily.com/releases/2010/10/101027145353.htm.

Van der Pol, M. (2011). Health, education and time preference. Health Economics, 20(8), 917-929. 
Van Kippersluis, H., O’Donnell, O., \& Van Doorslaer, E. (2011). Long-run returns to education. Does schooling lead to an extended old age? Journal of Human Resources, 46(4), 695-721.

Watt, R.G. (2007). From victim blaming to upstream action: tackling the social determinants of oral health inequalities. Community Dentistry and Oral Epidemiology, 35(1), 1-11.

Wennström, J.L., Serino, G., Lindhe, J., Eneroth, L., \& Tollskog, G. (1993). Periodontal conditions of adult regular dental care attendants. A 12-year longitudinal study. Journal of Clinical Periodontology, 20(10), 714-722. 